\title{
A new approach to the derivation of dynamic information from ionosonde measurements
}

\author{
L. Liu, X. Luan, W. Wan, B. Ning, and J. Lei \\ Wuhan Ionospheric Observatory, Wuhan Institute of Physics and Mathematics, The Chinese Academy of Sciences, Wuhan, \\ 430071, P. R. China
}

Received: 31 October 2002 - Revised: 9 May 2003 - Accepted: 13 May 2003

\begin{abstract}
A new approach is developed to derive dynamic information near the peak of the ionospheric F-layer from ionosonde measurements. This approach avoids deducing equivalent winds from the displacement of the observed peak height from a no-wind equilibrium height, so it need not determine the no-wind equilibrium height which may limit the accuracy of the deduced winds, as did the traditional servo theory. This approach is preliminarily validated with comparisons of deduced equivalent winds with the measurements from the Fabry-Perot interferometer, the Millstone Hill incoherent scatter radar and with previous works.

Examples of vertical components of equivalent winds (VEWs), over Wuhan $\left(114.4^{\circ} \mathrm{E}, 30.6^{\circ} \mathrm{N}, 45.2^{\circ} \mathrm{dip}\right)$, China in December 2000 are derived from Wuhan DGS-256 Digisonde data. The deduced VEWs show large day-to-day variations during the winter, even in low magnetic activity conditions. The diurnal pattern of average VEWs is more complicated than that predicted by the empirical Horizontal Wind Model (HWM). Using an empirical electric field model based on the observations from Jicamarca radar and satellites, we investigate the contributions to VEWs from neutral winds and from electric fields at the F-layer peak. If the electric field model is reasonable for Wuhan during this period, the neutral winds contribute mostly to the VEWs, and the contribution from the $\boldsymbol{E} \times \boldsymbol{B}$ drifts is insignificant.
\end{abstract}

Key words. Meteorology and atmospheric dynamics (thermospheric dynamics) - Ionosphere (ionosphere-atmosphere interaction; instrument and techniques)

\section{Introduction}

The development of ionospheric physics now depends very much on our knowledge of dynamic information/processes in the thermosphere-ionosphere coupling system. Considerable experimental and theoretical evidences show that the ionospheric F-layer is strongly influenced by neutral winds and

Correspondence to: L. Liu (lliu@wipm.ac.cn) electric fields (e.g. Rishbeth, 1967; Rishbeth et al., 1972; Titheridge, 1995b), i.e. the ionospheric plasma movements result mainly from the drag effects of neutral winds and the electrodynamic drift effects of large-scale electric fields (Rishbeth et al., 1978; Titheridge, 1995a), in addition to diffusion of gravity and pressure gradients. In fact, equatorward winds will drag the ionization upward along magnetic field lines, and eastward electric fields will lift up the plasma across the magnetic field lines. As a result, the F-layer rises. Reversely, poleward winds and westward electric fields will decrease the F-layer heights.

Much information about neutral winds and electric fields at ionospheric heights has been obtained with different methods in the past decades. The direct or indirect measurements with incoherent scatter radars (ISR) (Fejer, 1991; Oliver et al., 1993; Buonsanto and Witasse, 1999; Zhang et al., 2001), satellites (Scherliess and Fejer, 1999) and Fabry-Perot interferometers (FPI) (e.g. Sipler et al., 1991; Biondi et al., 1999) have contributed much to our understanding of thermospheric neutral winds and vertical ionization drifts. Although measurements from ISR, FPI and satellites may provide reliable neutral winds and electric fields, the measurements are limited to few locations and periods, due to the expensive cost of instruments and other related reasons. In contrast, the calculation from first principal or theoretical models, such as the NCAR/TIE-GCM model (Richmond et al., 1992), has no limit of locations and periods, but their results generally represent the average properties.

To some extent, deriving dynamic information (winds or electric fields) from ionosonde data (e.g. Miller et al., 1986; Zhang et al., 1995; Titheridge, 1995a; Dyson et al., 1997), which may be called indirect measurements, can partially overcome the above-mentioned disadvantages and supply the required wind information. This method is reliable and applicable most of the time. The regularly archived database for a wide range of sites and conditions from many ionosondes operating all over the world is readily available. This derivation approach will surely enrich our knowledge of neutral winds and electric fields, especially for the equatorial regions and 
low latitudes, where other ground-based measurements are indeed very limited.

The idea of deriving winds or electric fields from ionospheric data, originally proposed by Rishbeth et al. (1972, 1978), comes from the fact that winds and electric fields play important roles in the ionosphere dynamic processes. The progress on this aspect has been well described by Titheridge (1995b).

Section 2 describes a new approach for deriving the equivalent winds from ionosonde data. A preliminary validation of the approach is given in Sect. 3. Examples of equivalent winds over Wuhan $\left(114.4^{\circ} \mathrm{E}, 30.6^{\circ} \mathrm{N}\right)$, derived from DGS-256 Digisonde data of Wuhan Ionospheric Observatory (WIO), China, are presented in Sect. 4.

\section{Derivation of equivalent winds from ionospheric data}

The evolution of the ionosphere is well described by the plasma transport equations. If the ionosphere is assumed horizontally stratified, the continuity equation for electron density, $N_{e}$, can be simplified as

$$
\frac{\partial N_{e}}{\partial t}=q-\sum_{n} \beta_{n} N_{e}-\frac{\partial}{\partial h}\left(N_{e} V_{z}\right) .
$$

Here, $t$ is time, $h$ is height, $q$ is the electron production rate, $\beta_{n}$ is the electron loss coefficient due to neutral species $n\left(\mathrm{~N}_{2}\right.$ and $\mathrm{O}_{2}$ ), and $V_{z}$ is the vertical plasma velocity. In the F-layer ionosphere, the variation in $V_{z}$ is caused by electric fields, neutral winds, and plasma diffusions. The loss of ionization is a two-step process, mainly involving chemical reactions between $\mathrm{O}^{+}$ions and $\mathrm{N}_{2}$ or $\mathrm{O}_{2}$, followed by rapidly dissociative recombinations of electrons with $\mathrm{NO}^{+}$and $\mathrm{O}_{2}^{+}$.

Integrating Eq. (1) from the peak height of the F-layer, $h m$, to the top $(h=\infty)$, we have

$$
\begin{aligned}
& \int_{h_{m}}^{\infty} \frac{\partial N_{e}}{\partial t} d h=\frac{\partial F N_{m}}{\partial t} \\
& =\int_{h_{m}}^{\infty} q d h-\int_{h_{m}}^{\infty} \sum_{n} \beta_{n} N_{e} d h-\Phi_{\infty}+N_{m}\left(V_{z m}-\frac{d h_{m}}{d t}\right) \\
& =q_{m} H-N_{m} \sum_{n} G_{n} \beta_{n m}-\Phi_{\infty}+N_{m}\left(V_{z m}-\frac{d h_{m}}{d t}\right) .
\end{aligned}
$$

Here, $\int_{h_{m}}^{\infty} N_{e} d h=F N_{m}, \int_{h_{m}}^{\infty} \beta_{n} N_{e} d h=N_{m} G_{n} \beta_{n m} \cdot q_{m} H$ is the integrated value of the electron production rate of the topside ionosphere, and $H$ is the scale height of atomic $\mathrm{O} . \Phi_{\infty}$ is the ionospheric plasma topside flux, and variables with subscript $m$ refer to values at the F-layer peak, so $N_{m}, q_{m}$ and $\beta_{n m}$ are the electron density, production rate and loss coefficients due to neutral species $n$ at the F-layer peak, respectively. $F$ and $G_{n}$ are the integral factors, which depend on the shape of the topside ionospheric profile. It is worthwhile to point out that any deviation of the assumption for the horizontal stratified ionosphere could be included in the $\Phi_{\infty}$ term to match the actual situation. Using incoherent scatter radar data, the actual shape of the topside ionosphere is found to be close to the situation in diffusive equilibrium (MeléndezAlvira et al., 1993), namely the topside ionosphere maintains a constant shape close to the Chapman alpha layer. Under this reasonable assumption, we have $F=2.8214 \mathrm{H}$, $G_{\mathrm{N}_{2}}=0.5217 \mathrm{H}$ for $\mathrm{N}_{2}$, and $G_{\mathrm{O}_{2}}=0.4641 \mathrm{H}$ for $\mathrm{O}_{2}$.

To avoid a difficulty (Rishbeth et al., 1978) in using $\Phi_{\infty}$ in Eq. (2), we adopt an approximate form introduced by Rishbeth et al. (1978)

$$
\begin{aligned}
\frac{\partial N_{m}}{\partial t} & =\frac{\partial N_{m}}{\partial t}+\left.\frac{\partial h_{m}}{\partial t} \frac{\partial N}{\partial h}\right|_{m} \\
& =\frac{d N_{m}}{d t}=q_{m}-c \sum_{n} \beta_{n m} N_{m}-\frac{\Phi_{\infty}}{F} .
\end{aligned}
$$

Here, $c$ is an empirical factor of order unity, which takes into account of effect of the transport process at the peak, meeting the agreement between Eqs. (2) and (3).

At the peak of the F-layer, $V_{z m}$ can be expressed as

$V_{z m}=W-W_{d} \sin I$.

$W_{d}$ is the plasma diffusion velocity along the magnetic field line, $I$ is the magnetic dip angle, and $W=\left(V_{w} \sin I+\right.$ $V_{e} \cos I$ ) is the vertical equivalent wind (positive upward), i.e. a combination of the vertical components of meridional neutral winds along the magnetic field lines, $V_{w}$, and of the drifts induced by the zonal electric fields, $V_{e}$, in the ionosphere.

Substituting Eqs. (3) and (4) into Eq. (2), we have

$W=\frac{d h_{m}}{d t}+\frac{F-H}{N_{m}} q_{m}+\sum_{n}\left(G_{n}-c F\right) \beta_{n m}+W_{d} \sin I$.(5)

Equation (5) is the basic equation for deducing dynamic information, or the vertical components of equivalent winds (VEWs), from ionosonde measurements. The neutral winds dominate VEWs at middle latitudes, while at the equatorial region the electric fields dominate the VEWs.

If not specified, in the following calculations, $W_{d}$, the diffusion velocity for $\mathrm{O}^{+}$ions, takes the expression used by Buonsanto and Witasse (1999), and the formula for the collision frequency between $\mathrm{O}^{+}$ions and $\mathrm{O}$ neutrals is taken from Pesnell et al. (1993). The neutral parameters (neutral concentrations and temperature) are provided by the MSIS86 model (Hedin, 1987), and ion and electron temperatures are taken from IRI-90 model (Bilitza, 1990). The value of $c$ may affect the value of derived winds, which has been thoroughly discussed by Buonsanto et al. (1997). Based on their investigation, we inherit the $c$ value introduced by Rishbeth et al. (1978), namely $c=1.33$ for day and $c=1.73$ for night.

\section{Validation of the approach}

The approach is preliminarily validated by comparing the deduced equivalent winds with observations and previous works. 


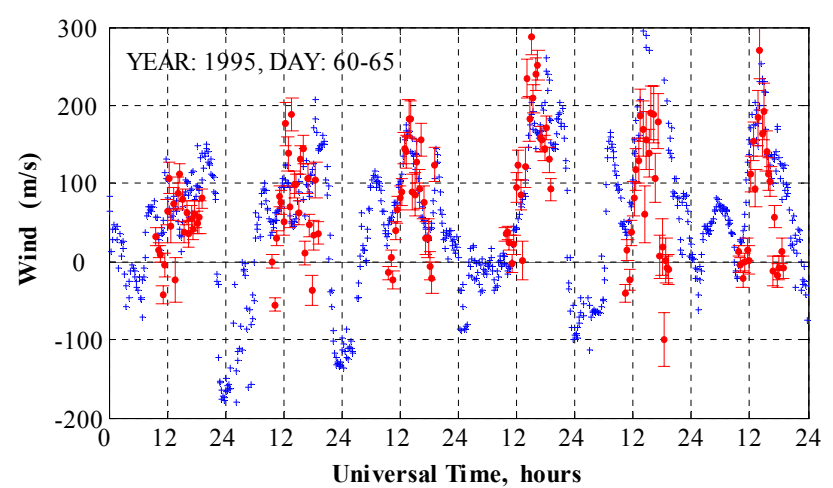

Fig. 1. A comparison of the FPI winds (dots with error bar) with the equivalent winds deduced from digisonde measurements ('+') during 1-6 March 1995, in Beveridge, Australia (See Dyson et al., 1997 for a detailed description of the campaign and their $h m \mathrm{~F} 2$ winds derived with the servo method).

3.1 Comparison with FPI winds during 1-6 March 1995 (Dyson et al., 1997)

A detailed description of the campaign on 1-6 March 1995 observed with a FPI and a DGS256 Digisonde at Beveridge $\left(37^{\circ} \mathrm{S}, 144^{\circ} \mathrm{E},-69.7^{\circ} \mathrm{Dip}\right)$, Australia, has been given by Dyson et al. (1997). It was a period of low solar activity and moderate to high magnetic activities. A comparison of the FPI winds and those deduced from Digisonde data with the traditional servo method during the March 1995 campaign has been carried out by Dyson et al. (1997). To avoid repeating the description of the campaign, we only show the winds derived from Digisonde data using our approach and the FPI winds (Fig. 1).

The $\boldsymbol{E} \times \boldsymbol{B}$ drift is neglected by Dyson et al. (1997) under an assumption about the contribution of the electric fields, which is much less than the neutral winds. To compare with the winds of Dyson et al. (1997), we also did not split the electric fields from the effective winds. Figure 1 shows that our results are very similar to theirs. There are still some differences between our results and the FPI winds, and between ours and the servo winds. The differences may be partly attributed to the poor quality of the ionograms (spread-F frequently appeared in the ionograms during the campaign.), partly to the error of the FPI winds, and also from the neutral parameters from the MSIS model (Hedin, 1987) during this period with moderate to high magnetic activities. We are collecting more FPI and ionosonde data for further validations.

\subsection{Comparison with Millstone Hill IS radar measurements}

During a campaign on days 177-180, 1990, the Millstone Hill Incoherent Scatter radar measured both electron density profiles and plasma drifts. The maximum electron density, $N m \mathrm{~F} 2$, and its height, $h m \mathrm{~F} 2$, and the equivalent winds derived from $N m \mathrm{~F} 2$ and $h m \mathrm{~F} 2$ using Eq. (5) are plotted in Fig. 2, and the ISR wind data are superimposed on the bottom panel. Figure 2 shows that the derived VEWs agree the mea-

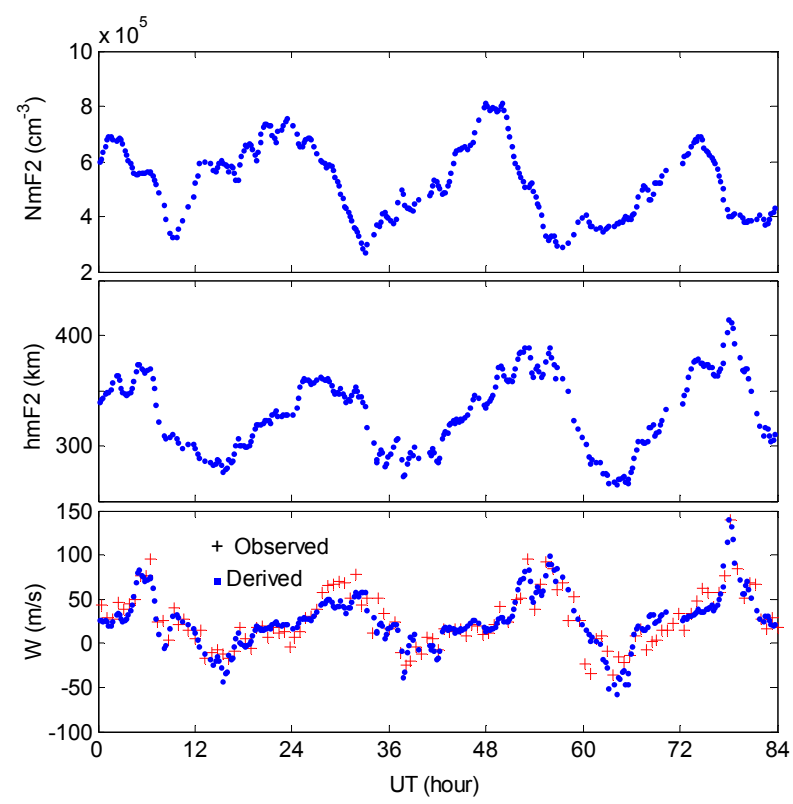

Fig. 2. $N m \mathrm{~F} 2, h m \mathrm{~F} 2$ observed with the Millstone Hill IS radar and a comparison of equivalent winds observed with IS radar ('+') and deduced ('o') with our method from observed $h m \mathrm{~F} 2$ and $N m \mathrm{~F} 2$ during the days 177-180, 1990.

surements quite well. Larger discrepancies between VEWs and the ISR measurements at some times may be due to the uncertainty of estimated $h m \mathrm{~F} 2$ and drifts from ISR measurements, which are associated with the radar range resolution.

\subsection{Comparison with published ion drift results}

The monthly average behavior of plasma drifts near the F2peak derived from ionosonde measurements has been investigated by Zhang et al. (1995) with the servo method at Wuhan and some Japanese stations (Okinawa, Yamagawa, Wakkanai). As an example for comparisons with their results, drifts at those stations in September, 1985 are recalculated using our technique, as shown in Fig. 3. These results are found to be consistent with theirs, not only in the local time variation, but also in latitudinal behaviors. The greatest differences between the methods are less than $25 \mathrm{~m} / \mathrm{s}$ at Wakkanai $\left(141.7^{\circ} \mathrm{E}, 45.4^{\circ} \mathrm{N}\right)$, and no more than $20 \mathrm{~m} / \mathrm{s}$ at the other three stations. It may be due to the differences in the methods for estimating the peak height from monthly median data and some parameters used in the derivations. It is suggested by Titheridge (1995a) that the uncertainty of 10 $20 \mathrm{~km}$ in peak heights may give overall errors of about $40 \mathrm{~m} / \mathrm{s}$ in calculated meridional winds.

\section{Examples of equivalent winds over Wuhan}

Ionospheric data from ionosonde observations have been achieved for more than 40 years in Wuhan. A DGS-256 Digisonde (Reinisch, 1996) routinely operates at Wuhan Ionospheric Observatory $\left(114.4^{\circ} \mathrm{E}, 30.6^{\circ} \mathrm{N}, 45.5^{\circ} \mathrm{dip}\right)$ and 


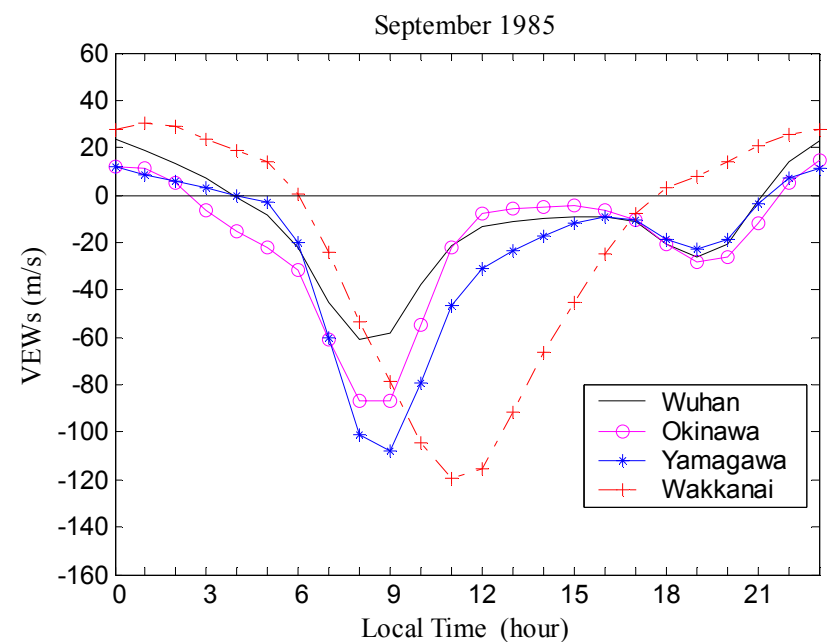

Fig. 3. Comparison of deduced equivalent winds between Wuhan and three other ionosonde stations (Okinawa $\left(127.8^{\circ} \mathrm{E}, 26.3^{\circ} \mathrm{N}\right)$, Yamagawa $\left(130.6^{\circ} \mathrm{E}, 31.2^{\circ} \mathrm{N}\right)$ and Wakkanai $\left(141.7^{\circ} \mathrm{E}, 45.4^{\circ} \mathrm{N}\right)$, in Japan during September, 1985.

has been updated in 1999. The ionograms were analyzed with the UMLCAR SAO-Explorer (http://ulcar.uml. edu/framesd.htm), a software tool developed by Center for Atmospheric Research, University of Massachusetts, Lowell. The profile inversion (Huang and Reinisch, 2001) calculates the electron density profile and outputs ionospheric characteristics, including $N m \mathrm{~F} 2$ and $h m \mathrm{~F} 2$. In this paper, we show only some examples of equivalent winds over Wuhan during a winter month under low magnetic activity conditions. The seasonal and solar cycle variations and other characteristics of equivalent winds has been presented in accompanied papers (Liu et al., 2003a, b).

Figure 4 shows the temporal variations of $f o \mathrm{~F} 2$, and $h m \mathrm{~F} 2$ over Wuhan during days 349-353 (14-18 December), 2000. The solar $10.7 \mathrm{~cm}$ flux index, F107, and the daily $A_{p}$ index for this period are plotted in the two top panels of Fig. 4. The deduced vertical component of equivalent winds (VEWs) is presented in Fig. 5.

For days 349-353, 2000, the $A_{p}$ index indicates quiet geomagnetic conditions, but the solar fluxes rise from 143.5 to 171.4. There are distinct day-to-day variations in $f o \mathrm{~F} 2$ and $h m \mathrm{~F} 2$ over Wuhan. The F-layer peak slowly lifts after sunrise, and reaches the daytime maximum near noon. Then it starts to decrease until 20:00-21:00 LT. Thereafter, it rapidly rises, and then turns downward at near midnight, which is referred to as the midnight descent, or midnight collapse (Nelson and Cogger, 1971). There is a rapid morning rise after the midnight descent, followed by a lowering of $h m \mathrm{~F} 2$ near sunrise. So the values of $h m \mathrm{~F} 2$ at Wuhan are generally lower in the daytime than at night, which can be well explained with the effects of thermospheric winds in the ionosphere (e.g. Rishbeth, 1967, 1972; Titheridge, 1995b). There are also obvious day-to-day variations in VEWs (Fig. 5) derived from ionospheric data (Fig. 4) based on our method men-

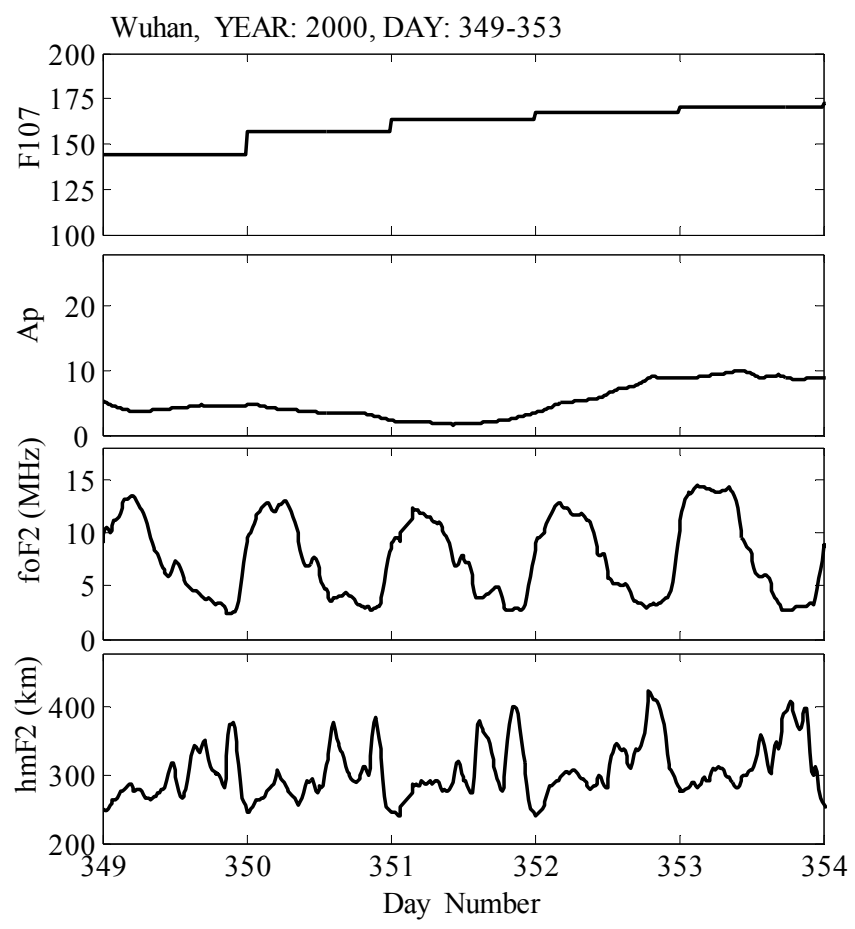

Fig. 4. Temporal variation of critical frequency, $f o \mathrm{~F} 2$, and peak height, $h m \mathrm{~F} 2$, over Wuhan during days 349-353 of the year 2000. The two top panels show the solar $10.7 \mathrm{~cm}$ flux index, F107, and the daily magnetic index, $A_{p}$.

tioned in Sect. 2. The overall VEWs are downward (negative values) in the daytime and during midnight descent, and upward (positive values) at night. It is consistent with the general pattern for the diurnal variation of meridional neutral winds (Rishbeth, 1972), i.e. the meridional wind blows to the pole in the daytime and reverse toward equatorward at night. VEWs vary from about -80 to $50 \mathrm{~m} / \mathrm{s}$, and the tendency of their variation is very similar to that of $h m \mathrm{~F} 2$.

Figure 6 illustrates $f o \mathrm{~F} 2$ and $h m \mathrm{~F} 2$ over Wuhan, and the F107 and $A_{p}$ indices for days 336-366, the entire month of December 2000. Figure 7 shows the derived VEWs. Solid lines at the first three panels of Fig. 8 show the diurnal variation of the median $f_{o} \mathrm{~F} 2, h m \mathrm{~F} 2$ in the whole month, and monthly averaged VEWs. All ionosonde measurements derived VEWs are also scatter plotted in Fig. 8 at the top three panels, respectively. And the bottom panel of Fig. 8 shows vertical components of equivalent winds (solid line), vertical components of meridional neutral winds (dot-dashed line) from the HWM model (Hedin et al., 1991) and $\boldsymbol{E} \times \boldsymbol{B}$ drift (Scherliess and Fejer, 1999) (line with circles), respectively.

Although the magnetic activity was low in this month, the $10.7 \mathrm{~cm}$ solar flux index varied between 117 and 175 . There are large day-to-day variations in $f o \mathrm{~F} 2, h m \mathrm{~F} 2$ and VEWs over Wuhan in December 2000. The maximum deviation of $f o \mathrm{~F} 2$ on individual days from its median values occurred in the late afternoon, especially near sunset, and the variability of $h m \mathrm{~F} 2$ is the largest at night. The VEWs are highly vari- 


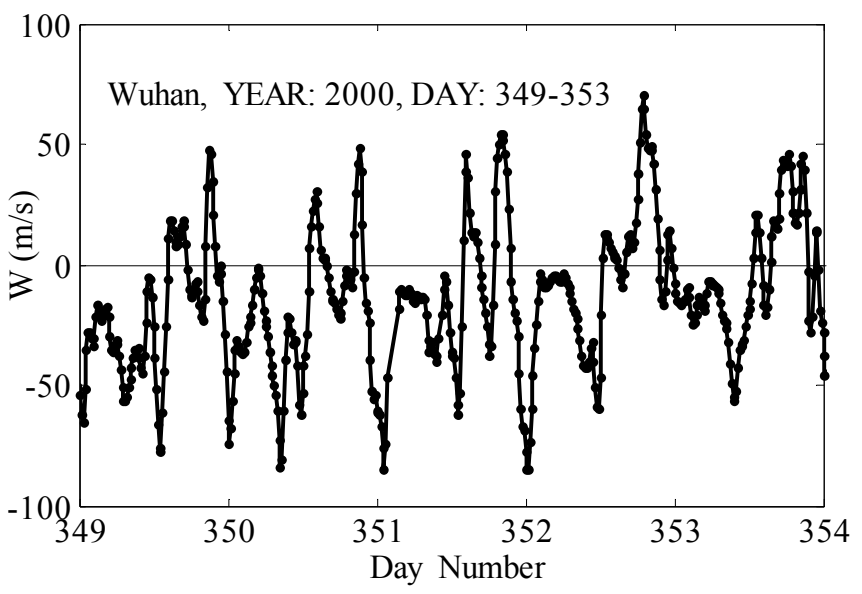

Fig. 5. Temporal variation of the vertical component of equivalent winds derived from the ionosonde measurements shown in Fig. 4. Positive upward.

able, but they spread less during the midday interval 04:0007:00 UT (Fig. 8).

The average VEWs over Wuhan in December 2000 is downward in the daytime, and upward at night, significantly descending and even reversing to downward near midnight. Their values varied from about -56 to $30 \mathrm{~m} / \mathrm{s}$, and the amplitudes of VEWs are larger in the day than at night. The December average VEWs also show similar features as neutral winds in the winter (Herrero et al., 1988), for example, the late afternoon maximum of the poleward wind, a significant night-time abatement, frequently reverses to poleward near midnight. The variation of VEWs on individual days is much larger than the average variation.

The ionospheric vertical movements are mainly driven by neutral winds and electric field induced drifts. To investigate the separate contributions to the VEWs over Wuhan, we also calculate, respectively, the vertical components of neutral meridional winds and of electrodynamic $\boldsymbol{E} \times \boldsymbol{B}$ drifts, which are shown in the bottom panel of Fig. 8. The neutral winds are provided by the HWM90 model (Hedin et al., 1991), and $\boldsymbol{E} \times \boldsymbol{B}$ drifts are taken from a global equatorial F-region vertical drift empirical model (Scherliess and Fejer, 1999). The values of the vertical component of the $\boldsymbol{E} \times \boldsymbol{B}$ drift are much smaller than that of VEWs. In other word, VEWs over Wuhan are mostly driven by neutral winds, hardly by $\boldsymbol{E} \times \boldsymbol{B}$ drifts, at least on the average for low magnetic activity conditions. Ion drift from the MU radar observations (Zhang et al., 2001) may also be taken as an option for the electric fields at low latitude. However, due to the very small contribution of the electric field, calculations with either of the models would hardly influence our conclusion here.

Compared with HWM winds, our results are in general agreement with the HWM winds, with the best agreement at night. It should be pointed out that the HWM model predicates winds over Wuhan with a predominant diurnal component, while the average values of our derived VEWs have a

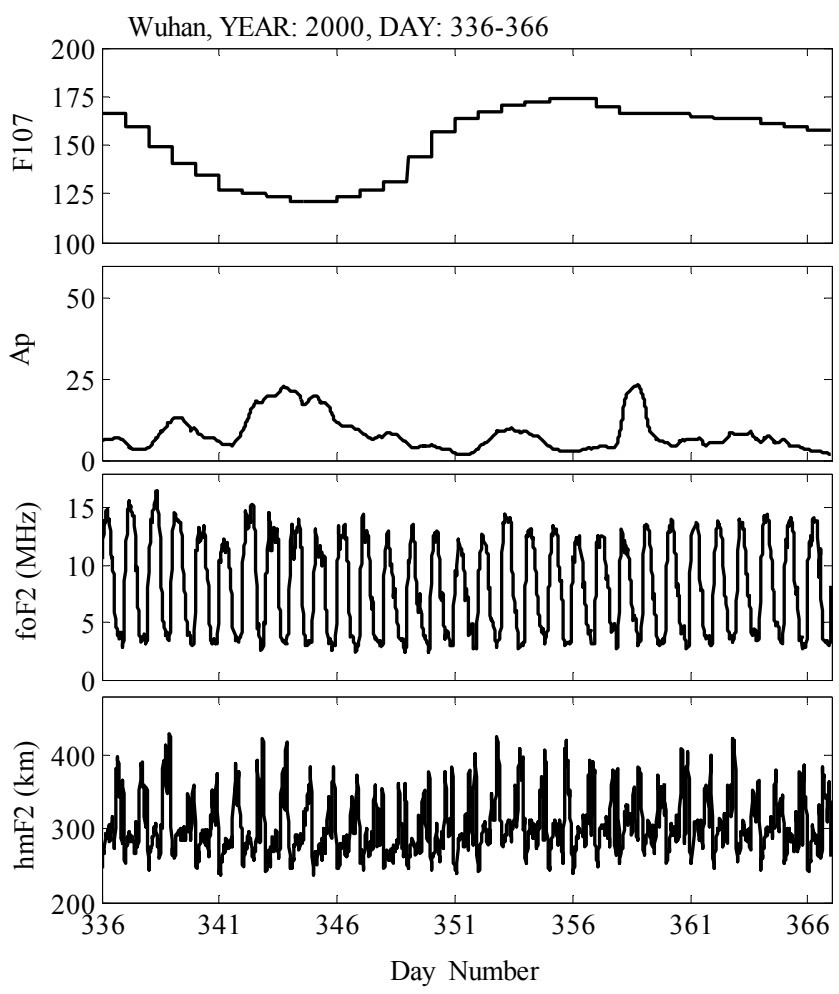

Fig. 6. Same as Fig. 4 but for days 336-366 (1-31 December), 2000 .

significant semidiurnal component in addition to the diurnal one.

\section{Summary and conclusion}

The neutral winds and electric fields play important roles in both the structure and the motion of the ionospherethermosphere system. Deducing dynamic information, winds and electric fields, or equivalent winds, from ionosonde observations is very useful for improving our understanding of the dynamics of the thermosphere-ionosphere coupling system. This technique is based on the traditional servo model (Rishbeth, 1967; Rishbeth et al., 1978; Miller et al., 1986, 1997; Gurubaran et al., 1995; de Medeiros et al., 1997), which assumes that: (1) the peak of the F-layer lies at a balance height controlled by diffusion and loss in the absence of applied winds and electric fields, which is the so-called no-wind reference height, or balance/equilibrium height; (2) the displacement of the peak from the no-wind reference height is due to winds and electric fields.

Although it has achieved great success (Titheridge, 1995a), the servo theory method needs a no-wind equilibrium height, which is difficult to be accurately determined due to the large time constants required for the ionosphere to reach an equilibrium state, especially in the daytime (Titheridge, 1993). To avoid this dilemma, a new approach for deriving equivalent winds from ionospheric data is introduced in the present paper. Our technique does not require a 


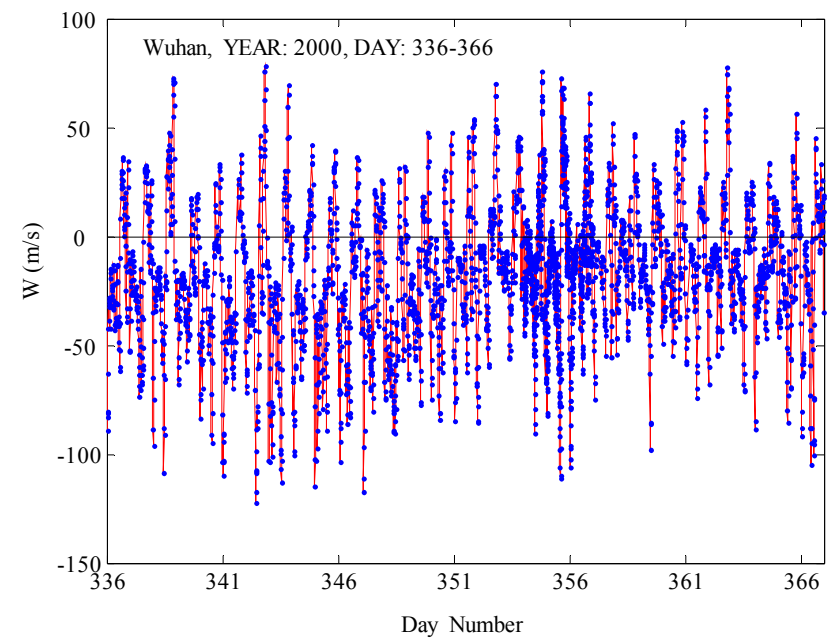

Fig. 7. Same as Fig. 5 but for days 336-366, 2000.

no-wind equilibrium height, and winds are not deduced from the difference between the height of F-layer peak and the nowind equilibrium height. The validation of our method has been carried out by comparing the FPI winds with those derived from $f o \mathrm{~F} 2$ and $h m \mathrm{~F} 2$ measurements during March 1995 (Dyson et al., 1997). A comparison of winds derived from ionosonde observations at Wuhan and three Japanese stations (Okinawa, Yamagawa, Wakkanai) during September, 1985 is also made with winds reported by Zhang et al. (1995). Another verification of the technique was made by comparison with Millstone Hill ISR measurements. These case comparisons indicate the usefulness of our approach.

Using this approach, we deduced the vertical component of equivalent winds in the F-layer over Wuhan in December 2000. Results show that the ionosphere and VEWs over Wuhan exhibit distinct day-to-day variations, even under low magnetic activity conditions. The variation of the vertical component of equivalent winds generally follows that of $h m \mathrm{~F} 2$. Over Wuhan, the average VEWs vary from about -56 to $30 \mathrm{~m} / \mathrm{s}$, with predominant diurnal and semidiurnal components. The VEWs are downward in the daytime and upward at night, having significant midnight abatement, even reversing to downward near midnight. The basic character of VEWs can be well explained by the thermospheric circulation theory, because the average VEWs are regulated by neutral winds, little by the $\boldsymbol{E} \times \boldsymbol{B}$ drifts, at least during the average cases and low magnetic activity conditions. More information of equivalent winds over Wuhan deduced from ionospheric data has been reported by Liu et al. $(2003 \mathrm{a}, \mathrm{b})$ in the 2002 COSPAR meeting.

Acknowledgements. L. B. Liu is grateful to Profs. P. L. Dyson and P. G. Richards for their courtesy in supplying the Beveridge FPI wind and Digisonde data. The Millstone Hill ISR data have been obtained from the Madrigal data system with the help of Dr. S.-R. Zhang. The computer codes of the MSIS, HWM, and IRI90 models were provided by the World Data Center-A. The $A_{p}$ and F107 data are downloaded from the SPIDR web: http:/spidr.ngdc.noaa.gov/.
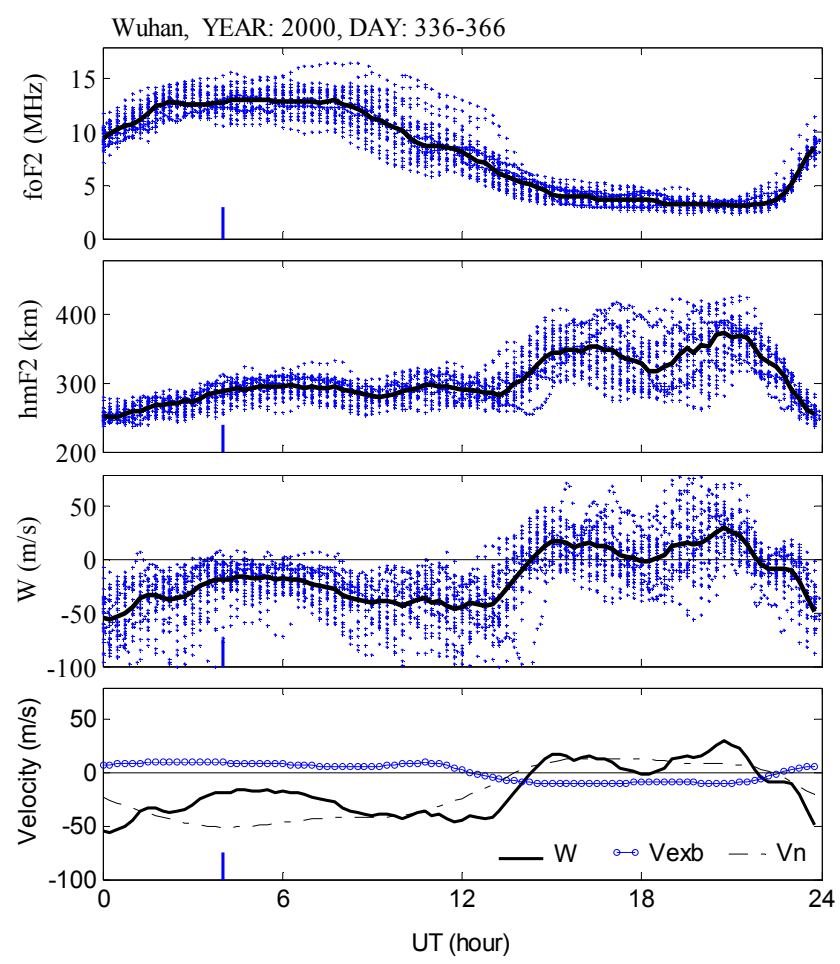

Fig. 8. Diurnal variations in median $f o \mathrm{~F} 2$ and $h m \mathrm{~F} 2$, and averaged vertical components of equivalent winds (solid line), and those of $\boldsymbol{E} \times \boldsymbol{B}$ drifts (line with circles) and neutral winds (dot-dashed line) during days 336-366, 2000. Superposed individual points present measured or deduced data in this month. Local noon is indicated with a short vertical line at the bottom of each panel.

This research was supported by the National Natural Science Foundation of China $(40274054,40134020)$ and Important Basis Research Project of China (G2000078407). We wish to acknowledge the referees for their very fruitful comments and suggestions to improve this paper.

Topical Editor U.-P. Hoppe thanks S. Zhang and another referee for their help in evaluating this paper.

\section{References}

Bilitza, D.: International reference ionosphere 1990, NSSDC/WDC-A-R \& S, 90-92, 1990.

Biondi, M. A., Sazykin, S. Y., Fejer, B. G., Meriwether, J. W., and Fesen, C. G.: Equatorial and low latitude thermospheric winds: measured quiet time variations with season and solar flux from 1980 to 1990, J. Geophys. Res., 104, 17 091-17 106, 1999.

Buonsanto, M. J., Starks, M. J., Titheridge, J. E., Richards, P. G., and Miller, K. L.: Comparison of techniques for derivation of neutral meridional winds from ionospheric data, J. Geophys. Res., 102, 14 477-14 484, 1997.

Buonsanto, M. J. and Witasse, O. G.: An updated climatology of thermospheric neutral winds and F-region ion drifts above Millstone Hill, J. Geophys. Res., 104, 24 675-24 687, 1999.

de Medeiros, R. T., Abdu, M. A., and Batista, I. S.: Thermospheric meridional winds at low latitude from measurements of F-layer peak height, J. Geophys. Res., 102, 14 531-14 540, 1997. 
Dyson, P. L., Davies, T. P., Parkinson, M. L., Reeves, A. J., Richards, P. G., and Fairchild, C. E.: Thermospheric neutral winds at southern mid-latitudes: A comparison of optical and ionosonde $h m \mathrm{~F} 2$ methods, J. Geophys. Res., 102, 27 189-27 196, 1997.

Fejer, B. G.: Low latitude electrodynamic plasma drifts: A review, J. Atmos. Terr. Phys., 53, 677-693, 1991.

Gurubaran, S., Sridharan, R., and Raghavarao, R.: Effects of neutral temperature on meridional winds estimated from ionospheric data, J. Atmos. Terr. Phys., 57, 1095-1101, 1995.

Hedin, A. E.: MSIS-86 thermospheric model, J. Geophys. Res., 92, 4649-4662, 1987.

Hedin, A. E., Biondi, M. A., Burnside, R. G., Hernandez, G., Johnson, R. M., Killeen, T. L., Mazaudier, C., Meiwether, J. W., Salah, J. E., Sica, R. J., Smith, R. W., Spencer, N. W., Wickwar, V. B., and Virdi, T. S.: Revised global model of thermosphere winds using satellite and ground-based observations, J. Geophys. Res., 96, 7657-7688, 1991.

Herrero, F. A., Mary, H. G., and Spencer, N. W.: Low latitude thermospheric meridional winds between 250 and $450 \mathrm{~km}$ altitude: AE-E satellite data, J. Atmos. TeRr. Phys., 50, 1001-1006, 1988.

Huang, X. and Reinsch, B. W.: Vertical electron content from ionograms in real time, Radio Sci., 36, 335-342, 2001.

Liu, L., Luan, X., Wan, W., Lei, J., and Ning, B.: Seasonal Behavior of equivalent winds over Wuhan derived from ionospheric data in 2000-2001, Adv. Space. Res., in press, 2003a.

Liu, L., Wan, W., Luan, X., Ning, B., and Lei, J.: Solar activity dependence of effective winds derived from ionospheric data at Wuhan, Adv. Space. Res., in press, 2003b.

Meléndez-Alvira, D. J., Burnside, R. G., and Walker, J. C. G.: Modeling the Arecibo nighttime F2-layer: 1. Overhead properties, J. Geophys. Res., 98, 5993-6011, 1993.

Miller, K. L., Torr, D. G., and Richards, P. G.: Meridional winds in the thermosphere derived from measurement of F2-layer height, J. Geophys. Res., 91, 4531-4535, 1986.

Miller, K. L., Lemon, M., and Richards, P. G.: A meridional wind climatology from a fast model for the derivation of meridional winds from the height of the ionospheric F2-region, J. Atmos. Terr. Phys., 59, 1805-1822, 1997.

Nelson, G. J. and Cogger, L. L.: Dynamical behaviour of the night- time ionosphere at Arecibo, J. Atmos. Terr. Phys., 33, 17111726, 1971.

Oliver, W. L., Yamamoto, Y., Takami, T., Fukao, S., Yamamoto, M. Y., and Tsuda, T.: Middle and upper atmosphere radar observations of ionospheric electric fields, J. Geophys. Res., 98, $11615-11627,1993$.

Pesnell, W. D., Omidvar, K., and Hoegy, W. R.: Momentum transfer collision frequency of $\mathrm{O}^{+}{ }_{-} \mathrm{O}$, Geophys. Res. Lett., 20, 13431346, 1993.

Reinisch, B. W.: Modern Ionosondes, in: Modern Ionospheric Science, edited by Kohl, H., Rüster, R., Schlegel, K., EGS Copernicus, 440-458, 1996.

Richmond, A. D., Ridley, E. C., and Roble, R. G.: A thermosphere/ionosphere general circulation model with coupled electrodynamics, Geophys. Res. Lett., 19, 601-604, 1992.

Rishbeth, H.: The effect of wind on the ionospheric F2-peak, J. Atmos. Terr. Phys., 29, 225-238, 1967.

Rishbeth, H.: Thermospheric winds and the F-region: a review, J. Atmos. Terr. Phys., 34, 1-47, 1972.

Rishbeth, H., Ganguly, S., and Walker, J. C. G.: Field-aligned and field-perpendicular velocities in the ionospheric F2-layer, J. Atmos. Terr. Phys., 40, 767-784, 1978.

Sipler, D. P., Hagan, M. E., Zipf, M. E., and Siondi, M. A.: Combined optical and radar wind measurements in the F-region over Millstone Hill, J. Geophys. Res., 96, 21 255-21 262, 1991.

Scherliess, L. and Fejer, B. G.: Radar and satellite global equatorial F-region vertical drift model, J. Geophys. Res., 104, 6829-6842, 1999.

Titheridge, T. E.: Atmospheric winds calculated from diurnal changes in the mid-latitude ionosphere, J. Atmos. Terr. Phys., 55, 1637-1659, 1993.

Titheridge, T. E.: The calculation of neutral winds from ionospheric data, J. Atmos. Terr. Phys., 57, 1015-1036, 1995a

Titheridge, T. E.: Winds in the ionosphere-a review, J. Atmos. Terr. Phys., 57, 1681-1714, 1995b.

Zhang, S.-R., Huang, X.-Y., and Su, Y.-Z.: Monthly average behavior and oscillation of derived ionospheric drifts, Report UAG 104, WDC-A for STP, NOAA, Boulder Co., January 1995.

Zhang, S.-R., Oliver, W. L., and Fukao, S.: MU Radar Ion Drift Model, Adv. Space Res., 27, 115-120, 2001. 